УДК [930.85+008]:001.89(470+571)

DOI: 10.32340/2414-9101-2021-2-49-54

О. В. Петренко, кандидат исторических наук Сибирский филиал Российского научно-исследовательского института культурного и природного наследия им. Д. С. Лихачёва (Омск, Россия) olgap26g12@mail.ru

\title{
ФУНДАМЕНТАЛЬНЫЕ ИССЛЕДОВАНИЯ ИСТОРИКО-КУЛЬТУРНОГО И ПРИРОДНОГО НАСЛЕДИЯ РОССИИ: ИНСТИТУЦИОНАЛЬНЫЙ АСПЕКТ
}

\begin{abstract}
Аннотация. Кратко охарактеризована деятельность современных российских научных сообществ, центров и организаций, занятых изучением отечественного историко-культурного и природного наследия; подчёркнута ведущая роль Российского научно-исследовательского института культурного и природного наследия им. Д. С. Лихачёва (г. Москва, Россия) и научных подразделений Российской академии наук (г. Москва, Россия) в проведении и координации фундаментальных исследований в отраслевом секторе науки в национальном масштабе. На взгляд автора, в настоящее время в России оформились два подхода к научному изучению историко-культурного и природного наследия: комплексный и проблемно-тематический. В 2020-2021 гг. анонсировано создание полидисциплинарных межрегиональных сообществ институтов (консорциумов), способных объединить административные, научные, образовательные, культурные и общественные ресурсы для решения исследовательских задач в каждом из упомянутых направлений.

Ключевые слова: научно-исследовательская работа в образовательных учреждениях, академическая наука, фундаментальные исследования в области сочииально-гуманитарного знания, историко-культурное и природное наследие России, сохранение и изучение историко-культурного наследия, Российская академия наук, Российский научно-исследовательский институт культурного и природного наследия им. Д. С. Лихачёва.
\end{abstract}

Спустя пятьдесят лет после принятия ЮНЕСКО (16 ноября 1972 г.), в результате постепенного внедрения в мировую общественную и научную практику конвенции об охране всемирного культурного и природного наследия, явление, унаследованное от предыдущих поколений, трансформируется в удобный для восприятия и применения концепт.

В едином диалогичном пространстве понятия «наследие» объединяются политические, исторические (репрезентирующие прошлое-настоящее-будущее в коллективную и индивидуальную память), научно-исследовательские и научно-практические, экологические, этические и эстетические, патриотические проблемы таких многомерных дуальных феноменов человеческой жизни, как Культура и Природа. Именно этот факт делает наследие в различных его коннотациях (историко-культурное, культурное, природное, научное, интеллектуальное, творческое и т. д.) столь популярным в политической, общественной, образовательной и научной среде. Выявление, изучение, сохранение, популяризация всемирного и национального наследия становится не только основой цивилизации, государственности, культурного и природного разнообразия, национальнокультурной идентичности, но и фактором устойчивого развития стран и регионов, общества и гармоничной личности. Фундаментальные и прикладные исследования наследия позволяют не только раскрыть контексты и условия, но также предложить инструменты и источники для успешной реализации этих важных «миссий».

Интересующая нас тема фундаментальных исследований историко-культурного и природного наследия России раскрывается в историографии с точки зрения саморефлексии в научных трудах [1-4], осмысления проблематики и методики исследований в мировой и отечественной практике, в качестве направления деятельности конкретных научных сообществ [5-8]. В данной 
работе предлагаем рассмотреть институциональный аспект таких исследований. Признавая, что эта проблема заслуживает обстоятельного изучения и презентации, выявим ее специфику и основные тенденции, кратко представим научные институты (учреждения, лаборатории, школы, коллективы), выбравшие объектом своих фундаментальных исследований историко-культурное и/или природное наследие России. Фундаментальные научные исследования определяем как экспериментальную или теоретическую деятельность, направленную на получение новых знаний об основных закономерностях строения, функционирования и развития человека, общества, окружающей среды [9]. Динамика появления и реализация интереса к изучению и сохранению отечественного наследия обусловила наше внимание к знаковому тридцатилетию, после официального присоединения Советского Союза к Конвенции ЮНЕСКО 12 января 1989 г. С этого времени термин «наследие» начинает активно использоваться в исследовательской и общественной практике вместе с традиционным для нашей страны понятием из области охраны объектов истории и культуры - «памятник».

Идеи российской интеллектуальной истории, институциональный историографический и исторический подходы, информационные технологии поиска, формализации и анализа (средствами персональных компьютеров и Рунета) разнообразных опубликованных и неопубликованных источников составили методику исследования. Необходимые данные были извлечены: из официальных, регламентирующих деятельность институтов текстов - приказы, уставы, научные планы, программы и отчеты; из юбилейных, научно-исследовательских, отчетных работ; с интернет-страниц официальных сайтов, ресурсов руководящих ведомств и партнеров, средств массовой информации, информационной системы Архивы Российской академии наук (далее - PAH) (isaran.ru), a также электронных библиотек «Научное наследие России» и eLIBRARY.RU.

Первым институтом, инициировавшим комплексное изучение наследия, стало возглавляемое академиком Д. С. Лихачевым общественное объединение Советский Фонд Культуры (учр. 12 ноября 1986 г.). Девиз Фонда: «Сохранять, осваивать и приумножать культурные ценности» реализовывался как в практическом, так и в научном плане. На страницах журнала объединения «Наше наследие» (изд. с 1988 г.) апробировался подход Д. С. Лихачева к наследию «как к явлению, включающему не только выдающиеся объекты и памятники истории и культуры, но и природно-историческую среду в целом, историю и жизнь местных сообществ, язык, обычаи и многие другие аспекты» [7, с. 17-18]. В рамках Фонда был сформирован и поддерживался Научнообщественный совет по уникальным историческим территориям, представители которого разрабатывали проблемы теории, методологии исследования и методики сохранения и возрождения историко-культурных территорий, проводили полевые исследования с участием специалистов историков, философов, географов, музейщиков, экономистов, социологов на Соловках и Валааме (1988-1989 гг.).

В 1992 г. при поддержке Д. С. Лихачева и участии членов Научно-общественного совета был создан первый и до сих пор единственный в нашей стране Российский научно-исследовательский институт культурного и природного наследия (с 1999 г. им Д. С. Лихачева). Директором-организатором стал ученый-географ, специалист по культурной географии и автор информационно-аксиологической концепции культурного ландшафта Ю. А. Веденин. В постановлении Правительства РФ подчеркивались ожидаемые функции учреждения - «научное обеспечение культурной политики и региональных программ по сохранению и использованию национального наследия в соответствии с Конвенцией ЮНЕСКО об охране всемирного культурного и природного наследия» [10], что институт успешно выполнял, разрабатывая методологию изучения, сохранения и использования культурного и природного наследия $[7,11]$. Междисциплинарным коллективом во главе со специалистами географами решались и прикладные проблемы: выявление, учет, картографирование и исследование национального наследия России (культурного и природного, материального и нематериального, морского и военного, археологического и этнографического); разработка комплексных территориальных программ исторических территорий, природных и культурных ландшафтов, создание региональных научно-образовательных, музейных и 
туристско-экскурсионных комплексов, с учетом специфики местного культурного и природного наследия, экологических и природоохранных аспектов [6, с. 96-157; 7, с. 22-34].

После «оптимизации» института в 2013-2014 гг. сохраняются почти все исследовательские направления и появляются новые: государственная культурная политика, актуализация наследия, изучение и проектирование музеев, культурно-психологическая и общефилософская теория наследования культуры, культура русского зарубежья, фундаментальные исследования культуры на основе цивилизационного и аксиологического подхода к наследию, культурологические и историко-философские основания коллективной исторической памяти. У института появляются Сибирский и Южный филиалы, наблюдается усиление этнографической и музейной, культурно-исторической и культурологической линии за счет присоединения к учреждению коллектива Российского института культурологии Министерства культуры РФ (далее - РИК), где с 1993 г. активно разрабатывались проблемы изучения и сохранения культурного наследия (научное направление «Историческая культурология» под руководством доктора культурологии Э. А. Шулеповой, РИК; этнографическая школа доктора исторических наук Н. А. Томилова; сектор сохранения и использования культурного наследия доктора исторических наук П. П. Вибе, СФ РИК) [6, с. 55-56; 12, с. 12].

Академическую линию фундаментальных исследований наследия представляют подразделения РАН. 26 мая 1992 г. Постановлением Президиума РАН был создан Научный совет РАН по изучению и охране культурного и природного наследия, в котором, как и в Институте наследия, объединили свои усилия гуманитарии и естественники (инициаторы и сопредседатели акад. доктор филологических наук Е. П. Челышев и доктор биологических наук В. Е. Соколов, позже доктор биологических наук Г. В. Добровольский). В Совет вошли известные ученые, академики как Д. С. Лихачев, руководители академических и отраслевых научных институтов как Ю. А. Веденин и директор РИК доктор культурологии К. Э. Разлогов, деятели высшего образования и культуры. В составе Совета 13 комиссий, выполняющих координационные, научно-консультативные и информационные функции, участвующие в организации и проведении научно-практических мероприятий, нацеленные на создание целостной научной концепции сохранения и изучения культурного и природного наследия, формирование к любому наследию уважительного и бережного отношения. С 2008 г. реализовывался подход к изучению наследия «сквозь призму культурно-природного синтеза и осмысления в этой связи цивилизационного пути России» [5, с. 15]. Похожая структура создана в 1992 г. в Санкт-Петербургском научном центре РАН.

Ученые отделений РАН в центре и регионах обращаются к изучению научного, интеллектуального, творческого наследия ученых РАН, российских философов, культурных деятелей, писателей и поэтов. Природное наследие в системе «мир-природа-население-хозяйство» изучается Институтом географии РАН и его подразделениями. Институт Степи Оренбургского федерального исследовательского центра УРО РАН предлагает комплексное изучение степей Северной Евразии как единого географического и историко-культурного пространства (истории, природопользования, ландшафтного и биологического разнообразия). Представители Отделения историко-филологических наук - Институт археологии РАН, Институт этнологии и антропологии РАН, лаборатории археологии, истории и этнографии Отдела гуманитарных исследований Южного научного центра РАН, Институт истории и археологии УРО РАН, Институт истории, археологии и этнографии народов Дальнего Востока ДВО РАН, Институт археологии и этнографии СО РАН и их подразделения (как Омская лаборатория) - включают в основные направления своих исследований изучение и сохранение культурного наследия (как правило, археологического и этнографического). Отметим междисциплинарные исследования центральных и региональных структур Отделения историко-филологических наук и Отделения общественных наук по Программе фундаментальных исследований Президиума РАН «Историко-культурное наследие и духовные ценности России» (2009-2011). Учеными раскрыты направления древнейшего творческого и археологического наследия, традиций и новаций в культуре и языках народов, цивилизационные и геополитические особенности истории и гражданского общества России, философское осмысление наследия, музейные и архивные фонды в изучении и презентации культурного наследия. С 2019 г. 
РАН делает особый акцент на роли культурного наследия и необходимости его изучения, что отражается в новой программе фундаментальных исследований.

С 2014 г. Российская академия художеств и Российская академия архитектурных и строительных наук работают по программе фундаментальных исследований 2013-2020 гг. с изучением методологии и теории историко-культурного наследия в своей области, судя по отчетам и докладам Президенту РФ, результаты исследований впечатляют.

Третью нишу фундаментальных исследований наследия закрывает научно-исследовательская работа, научные школы и лаборатории вузов. С утверждением образовательных программ по специальности 51.03.4 (Музеология и охрана объектов культурного и природного наследия) появляются или меняют названия при объединении с археологами и этнографами соответствующие кафедры, появляются исследования по проблемам наследия.

Фронтальный просмотр научных разделов российских вузов выявил следующие лаборатории по проблемам изучения культурного наследия: в Санкт-Петербургском государственном университете (Лаборатория археологии, исторической социологии и культурного наследия им. Г. С. Лебедева); в Дальневосточный федеральном университете (Лаборатория комплексных археологических исследований и экспертиз объектов культурного наследия); в Алтайском государственном институте культуры (далее - АГИК) («Культурное наследие Алтая»); в Омском государственном университете им. Ф. М. Достоевского (Лаборатория этноархеологии). В диалоге историков с экономистами, социологами, экологами, географами, инженерами проводятся междисциплинарные исследования исторического (индустриального, культурного и природного) наследия Лаборатории экологической и технологической истории Санкт-Петербургской школы гуманитарных наук и искусств Национального исследовательского университета «Высшая школа экономики». Инновационные научные школы обнаружены в Барнауле - «Изучение, сохранение и трансляция историко-культурного наследия» (АГИК), в Москве - междисциплинарная научно-образовательная школа Московского государственного университета им. М. В. Ломоносова «Сохранение мирового культурно-исторического наследия», в Казани - Высшая школа исторических наук и всемирного культурного наследия Казанского федерального университета (далее - КФУ).

Следующая форма осуществления научных проектов - Научно-образовательные центры (далее - НОЦ). Отметим: НОЦ «Музей и культурное наследие» кафедры музеологии, культурного и природного наследия Томского государственного университета; НОЦ «Региональное историкокультурное наследие и кросс-культурные связи» Института истории и международных отношений Саратовского национального исследовательского государственного университета, участники которого изучают научное знание, образование, имагологию и историческую память народов Нижнего Поволжья, важные части и условия бытования исторического наследия. Особо выделим НОЦ Ресурсный центр «Всемирное культурное наследие» КФУ (руководитель доктор исторических наук Р. М. Валеев), где проводятся исследования с опорой на подходы Ю. А. Веденина и П. М. Шульгина по основным направлениям Института Наследия (до 2013 г.): методология и методика изучения и сохранения наследия; этнокультурное наследие; исторические и традиционные технологии; международный опыт в сфере сохранение и использования наследия; разработка принципов и программ эффективного использования наследия для развития культурно-познавательного туризма, создания музеев заповедников и охранных территорий; разработка научных принципов картографирования наследия и создания атласа «Культура и культурное наследие Республики Татарстан». С 2018 г. в издательстве КФУ продолжает издаваться один из журналов Института Наследия «Наследие и современность».

Новой формой осуществления комплексных и полидисциплинарных исследований становятся консорциумы (лат. consortium - сообщество) - объединения учреждений науки, образования, архивов и музеев и других институтов для исследования общей проблемы. В 2020-2021 гг. заключено два соглашения на создание подобных объединений интересующей нас тематики - Консорциум «Мировое историко-культурное наследие Арктики» (СПБ) и Университетский консорциум «Понтийская зона межцивилизационных контактов в древности и Средние века» (Крым). 
Исследование показало, что в сфере фундаментального изучения историко-культурного и природного наследия сохраняются две тенденции. Первая - это стремление к комплексному познанию культурного и природного наследия России, вторая - к междисциплинарным проблемнотематическим проектам. Несмотря на увеличение количества изучающих наследие институтов, ведущую роль в фундаментальных исследованиях сохраняют научно-исследовательский Институт наследия им. Д. С. Лихачева и научные подразделения РАН. Однако, в 2020-2021 гг. на исследовательском поле появляются и новые игроки - полидисциплинарные межрегиональные сообщества институтов, способные объединить науку, образование, культуру, общество и власть для решения поставленных задач. Ограниченный объем публикации не позволил уделить должного внимания познавательному, историческому, социокультурному и экономическому контекстам, влиянию экспертной и координирующей деятельности ЮНЕСКО и РАН, а также роли персонального фактора - идеям и творчеству знаковых личностей, ученых и практиков наследиеведов. На перспективу осталось также подробное рассмотрение специфики деятельности, тематики и познавательных подходов, инновационных проектов, научных и научно-практических результатов, а также площадок их апробации - научных трудов, периодических изданий, научных дискуссий. По итогам работы планируется также уточнение, соответствующее оформление и размещение в сети Интернет базы данных исследователей (институтов и персоналий) наследия, что будет способствовать изучению и популяризации проблем культурного и природного наследия России.

\section{Список литературь}

1. Культурный ландшафт как объект наследия / Е. Д. Андреева [и др.] ; отв. ред. Ю. А. Веденин, М. Е. Кулешова. - Москва : Санкт-Петербург : Ин-т Наследия, 2004. - 620 с.

2. Веденин, Ю. А. География наследия. Территориальные подходы к изучению и сохранению наследия. - Москва : Новый хронограф, 2018. - 470 с. - (Социальное пространство).

2. Культурологический сборник: исследования по культуре Западной Сибири и Северного Казахстана. К 25-летию Сибирского филиала Института Наследия / гл. ред. И. А. Селезнёва ; отв. ред. Т. Н. Золотова ; ред. Ю. Р. Горелова. - Москва : Ин-т Наследия, 2019. - 170 с.

3. Труды Отделения историко-филологических наук : [2019] : [сб. ст.] / отв. ред. А. П. Деревянко. - Москва : Наука, 2020. - 307 с.

5. Добровольский, Г. В. Сохраняя великое наследие: к 20-летию со дня учреждения научного Совета РАН по изучению и охране культурного и природного наследия / Г. В. Добровольский, Е. П. Челышев // Пространство и Время. - 2012. - № 2. - С. 11-17.

6. Наука о культуре: история Российского НИИ культурного и природного наследия им. Д. С. Лихачёва (Института Наследия) и Центрального НИИ методов краеведческой работы (Российского института культурологии) / отв. ред. С. Ю. Житенёв. - М : Рос. науч.-исслед. ин-т культурного и природного наследия им. Д. С. Лихачёва , 2017. - 271 с.

7. В фокусе наследия : сб. ст., посвящ. 80-летию Ю. А. Веденина и 25-летию создания Рос. науч.-исслед. ин-та культурного и природного наследия / [составитель и ответственный редактор М. Е. Кулешова]. - Москва : Ин-т географии РАН, 2017. - 686 с.

8. Институт археологии РАН: 100 лет истории / [отв. ред. Н. А. Макаров]. - Москва: ИА РАН, 2019. - 319 с. : цв. ил.

9. О науке и государственной научно-технической политике : фед. закон № 127-Ф3 от 23 авг. 1996 г. // Консорциум «Кодекс», электронный фонд правовой и нормативно-технической информации : [сайт]. - Москва, 1991-2021. - URL: https://docs.cntd.ru/document/ 9028333 (дата обращения: 20.03.2021).

10. О создании Российского научно-исследовательского института культурного и природного наследия : постановление Правительства Рос. Федерации № 241 от 13 апр. 1992 г. // Консорциум «Кодекс», электронный фонд правовой и нормативно-технической информации : [сайт]. Москва, 1991-2021. - URL: https://docs.cntd.ru/document/901606346 (дата обращения: 15.03.2021).

11. Петренко, О. В. Теоретические основания изучения объектов наследия: опыт Российского научно-исследовательского института культурного и природного наследия им. 
Д. С. Лихачёва // Современные тенденции в развитии музеев и музееведения : матер. IV всеросс. с междунар. участием науч.-практ. конф. (Новосибирск, 22-23 окт. 2020 г.). - Новосибирск : ИПЦ НГУ, 2020. - С. 62-75.

12. Алисов, Д. А. Научная и научно-организационная деятельность Сибирского филиала Российского института культурологии за 15 лет / Д. А. Алисов, Н. А. Томилов // Культурологические исследования в Сибири. - 2008. - № 2. - С. 11-26.

Olga V. Petrenko, Ph. D. in History Siberinan Branch of Likhachev Russian Research Institute for Cultural and Natural Heritage (Omsk, Russia) olgap26g12@mail.ru

\title{
BASIC RUSSIAN HISTORICAL, CULTURAL AND NATURAL HERITAGE RESEARCH: INSTITUTIONAL ASPECT
}

\begin{abstract}
The article briefly describes research activities of the today's Russian communities engaged in work on study of domestic historical, cultural, and natural heritage. The author stresses out the leading role of Likhachev Russian Research Institute for Cultural and Natural Heritage (Moscow, Russia) and units of the Russian Academy of Sciences (Moscow, Russia) in conducting and coordinating basic research practices in related sector of science in Russia-wide level. On the author's view, at the current time there are two approaches to studying historical, cultural, and natural heritage in Russia: complex and problem-thematic.In 2020-2021, there were announced deveploping multidisciplinary inter-regional communities of institutes (consortiums) that will be able to accumulate administravive, scientific, educational, cultural, public sources for attacking the immediate research problems.

Keywords: research work in educational institutions, academic science, basic research in the humanities, historical, cultural, and natural heritage of Russia, preservasion and study of historical and cultural heritage, Russian Academy of Science, Likhachev Russian Research Institute for Cultural and Natural Heritage.
\end{abstract}

УДК 911.375:910.4-051(571.150-25)“1701/1900”

DOI: $10.32340 / 2414-9101-2021-2-54-61$

М. В. Рыгалова, кандидат исторических наук Алтайский государственный университет (Барнаул, Россия) mariya_rygalova@mail.ru

\section{БАРНАУЛ ГЛАЗАМИ ИССЛЕДОВАТЕЛЕЙ И ПУТЕШЕСТВЕННИКОВ ХVII-ХІХ ВВ.}

\author{
Исследование выполнено при финансовой поддержке \\ Совета по грантам Президента Российской Федеращии, \\ проект № $M K-4173.2021 .2$
}

Аннотация. Охарактеризован вклад отечественных и зарубежных исследователей и путешественников XVIII-XIX вв. (Э. Г. Лаксмана, П. С. Палласа, К. Ф. Ледебура, А. А. Бунге, К. А. фон Мейера и др.), побывавших с деловыми, научными или личными целями на территории КолываноВоскресенского горного округа (Российская империя), в формирование культурно-исторического образа Барнаула как горнозаводского города. Барнаул в 30-х гг. XVIII в. становится центром горнозаводского производства, что накладывает свой отпечаток на производственно-экономический, архитектурный, культурный и бытовой облик города. По впечатлениям исследователей 